\title{
Phase Equilibria in Transition Metal Al-Ga-N Systems and Thermal Stability of Contacts to AIGaN*
}

\author{
K.O. SCHWEITZ ${ }^{1}$ and S.E. MOHNEY ${ }^{1,2}$ \\ 1.- The Pennsylvania State University, Department of Materials Science and Engineering, \\ University Park, PA 16802, USA. 2._E-mail: mohney@ems.psu.edu
}

Erratum to "Phase Equilibria in Transition Metal Al-Ga-N Systems and Thermal Stability of Contacts to AlGaN", by K.O. Schweitz and S.E. Mohney [J. Electron. Mater. 30, 175 (2001)].

The journal regrets that some of the authors' corrections to the page proofs were not made. These include Eq. (1) and ref. 29, which, respectively, should be

$$
\Delta_{\mathrm{f}} \mathrm{G}_{\mathrm{T}}=\Delta_{\mathrm{f}} \mathrm{H}_{298 \mathrm{~K}}^{\circ}+\int_{298 \mathrm{~K}}^{\mathrm{T}} \Delta \mathrm{C}_{\mathrm{P}} \mathrm{dT}-\mathrm{T}\left(\Delta_{\mathrm{f}} \mathrm{S}_{298 \mathrm{~K}}^{\circ}+\int_{298 \mathrm{~K}}^{\mathrm{T}} \frac{\Delta \mathrm{C}_{\mathrm{P}}}{\mathrm{T}} \mathrm{dT}\right)
$$

and

29. A.Y. Polyakov, N.B. Smirnov, A.V. Govorkov, D.W. Greve, M. Skowronski, M. Shin, and J.M. Redwing, MRS Internet J. Nitride Semicond. Res. 3, 37 (1998). 